\title{
THE RESPIRATORY EXCHANGE IN CRETINISM AND MONGOLIAN IDIOCY
}

\author{
BY G. B. FLEMING \\ (From the Royal Hospital for Sick Children, Glasgow)
}

AT one time there was no sharp distinction drawn between Mongolian idiocy and cretinism. Though the chief points in the differential diagnosis are clearly given by many authorities $(1,10)$, even now the conditions are too frequently confused. In cretinism there is insufficiency of the internal secretion of the thyroid gland, and this is almost certainly the cause of the symptoms, while in Mongolian idiocy no cause has been discovered.

A striking feature of all diseases in which there is hypothyroidism is the low basal metabolism, and cretinism is no exception to this rule $(3,6)$. Though the metalolism of a considerable number of fairly old cretins has been examined, I can only find records of observations on one cretinoid infant (11). In all there is a marked lowering of the basal metabolism. In Talbot's case (the infant) there was a very low basal metabolism before treatment began, and after ten days of thyroid treatment this was greatly increased. Unfortunately there was much greater muscular activity in his second experiments, and consequently it is not possible to say how much the metabolism was raised by activity and how much by the drug. This is a difficulty which it is not easy to overcome in such cases. The untreated cretin is extremely lethargic, and as a rule it is easy to get a sufficiently long period of repose to examine the respiratory exchange; on the other hand, the cretin when treated with thyroid soon becomes extremely restless, and usually rather intractable. No doubt this is a sign of improvement, but it does not facilitate investigation of the basal metabolism. In two cases which I have had the opportunity to examine, numerous estimations of the basal metabolism were made, and it has been possible to get comparable conditions of muscular activity before and during treatment in both of them.

I do not know of any observations on the basal metabolism of Mongols, so in order further to differentiate them from cretins $I$ thought it might be of interest to examine the respiratory exchange in some of these.

In both cretinism and Mongolism there is always marked under-development, and it is difficult to know whether to compare their metabolism to that of normal children of the same weight or the same age. The work of Benedict

[Q. J. M., Oct., 1922.] 
and Talbot (2) provides us with data which enable us to make these comparisons. Their figures for the basal metabolism of normal children are used throughout this paper. The cretin owes a considerable proportion of its weight to myxoedematous tissue which is no doubt metabolically inactive. The Mongol, on the other hand, may be fairly well nourished, though the state of nutrition seems to show great individual variation, but there is always lack of muscular tone. In short, the Mongol is an undersized child, and the cretin, though also undersized, is loaded with a mass of metabolically inactive tissue which may amount to 10 or 20 per cent. of its total body-weight.

The Benedict-Talbot apparatus was used for the determination of the respiratory exchange. This is a closed circuit system and gives very accurate results. The technique followed was the same as that described by me in a previous paper (4). Alcohol control tests were frequently employed in order to check the accuracy of the apparatus. In each experiment a graphic record of the movements of the child was taken. As it is impracticable to reproduce these the degree of activity is indicated by numbers. An activity of I means practically no movement, the subject probably being asleep. Periods with slight movement are designated with the number II, and III, IV, V, and VI each apply to periods where there is increasing movement; with an activity of VI the subject is moving throughout the experiment and probably crying. The heat output was calculated from the respiratory quotient and the amount of oxygen used.

\section{The Basal Metabolism in Cretinism.}

J. D., male, aged 1 year 11 months.

Admitted 19.9.21. Normal labour, healthy at birth, weight 5.4 kilos. Breastfed for $9 / 12$. Throve well, was able at $9 / 12$ to sit up, but never walked. Since that age the child had not developed. He had gradually become more and more lethargic, and although at one time he could say a few words he could not speak at the time of admission. The skin had always been dry and the feet and hands cold and blue.

On admission the child was seen to be a typical cretin with coarse bloated features, protruding tongue, harsh dry skin, hands and feet cold and blue. Apparently very fat. Large umbilical hernia. Fontanelle unduly open, no teeth, hoarse cry. Weight, 8.68 kilos; length, $68 \mathrm{~cm}$. ; sitting height, $46 \mathrm{~cm}$.

Sugar tolerance. 4.10.21. 57 grm. glucose given fasting. No glycosuria. 6 months.

$X$-ray of wrist showed ossification equal to that of a child of under

On 23.10.21 put on thyroid, gr. $\frac{1}{2}$, three times a day. This was increased to gr. $\mathrm{j}$ twice daily on the $27 \mathrm{th}$, and on Nov. 5 to gr. $\mathrm{j}$ thrice daily. Within a few days of the commencement of thyroid treatment loss of weight commenced and child became brighter. Thyroid treatment was continued till Nov. 19, and by this time there had been considerable loss of weight, $0 \cdot 7$ kilo, the skin had become warmer and less dry, and the child had become quite bright and active. Thyroid was stopped from Nov. 19 till Dec. 14. During this time the weight increased $0.9 \mathrm{kilo}$, the child became lethargic, the skin dry, and the extremities cold, though his general condition was not so markedly cretinoid as it was on admission. On Dec. 15 thyroid treatment was recommenced (gr. $j$ twice daily); the weight immediately bcgan to diminish, and the child soon became bright and 
active once more. He was discharged from hospital on Dec. 27. On 2.2.22 he was readmitted to hospital. Thyroid treatment had been continued at his home. On admission he weighed 8.4 kilos, and he measured $71.5 \mathrm{~cm}$. On Feb. 14 his sugar tolerance was tested. He was able to take $55 \mathrm{grm}$. glucose without glucose appearing, in the urine.

On Feb. 22 he developed measles and was sent to Ruchill Fever Hospital.

A. D., female, aged 4 years 8 months.

Admitted to the Royal Hospital for Sick Children on 14.2.22. The child was said to have thriven till 1 year old. She was breast-fed for $1 \frac{1}{4}$ years. She always had a poor appetite and was markedly constipated. She cut her first tooth at the age of 16 months. Her hands and feet are said always to have been cold and blue. She had never talked properly, but recently she had been able to say a few words. Eight months previously she was able to walk with assistance, but recently had not even been able to do this.

On admission the child was seen to be a typical cretin. The skin and hair were dry. She was apparently very fat. Weight, 11 kilos; length, $74.5 \mathrm{~cm}$.; sitting height, $49 \mathrm{~cm}$. The hands and feet were cold and puffy. The face was heavy looking. The eyebrows were fairly well developed. She was very lethargic. She had a hoarse cry. She could not stand. The heart appeared normal. There was some bronchitis. The abdomen was protruding and there was a slight umbilical hernia. The tongue was square and usually protruding. She had the full complement of teeth. The von Pirquet reaction was negative. The urine was normal.

Sugar tolerance test. $60 \mathrm{grm}$. of glucose were given fasting. There was no glycosuria.

Adrenalin test. 0.5 c.c. adrenalin 1/1000 injected intramuscularly. No reaction; no glycosuria.

$X$-ray of wrists showed ossification equal to that of a child of 1 year.

Thyroid treatment was commenced on 24.2 .22 , gr. $\mathrm{j}$ three times a day. This was increased to gr. ij twice daily on 3.3 .22 , but was reduced to the original dose on 15.3.22, and again increased to gr. ij twice daily on 19.3.22. This dose was continued till the child was discharged on 4.5.22.

During the course of treatment with thyroid the child lost 2 kilos in weight, and there was a vast improvement in the general and mental conditions. By May 4 the child was trying to talk. It was crawling about very actively, taking its food well, and the skin was soft and moist.

Table I gives the results of the respiratory exchange examinations in these two children. Both children were fed on ordinary mixed diet, and always drank about 150 c.c. of milk about forty minutes before the commencement of an experiment. In the first case, J.D., it will be seen that the metabolism was very low before thyroid was given. The total basal heat output per twenty-four hours was about what would be expected from an infant of about 6 months old. The administration of thyroid increased the metabolism by about 40 per cent. When thyroid was stopped there was a fall in the heat output, but this did not occur promptly. It took about three weeks for the effect of the thyroid treatment to wear off, and even then the metabolism did not fall to the original low level. On the resumption of thyroid treatment the metabolism immediately increased once more. The physical and mental condition of the child improved with the increase in the basal metabolism, and when treatment was interrupted there was a distinct retrogression in the general and mental condition.

In the second case, A. D., a similar low basal metabolism was found, and 
this rose with thyroid treatment (Table I). Unfortunately it was extremely difficult to obtain periods of muscular repose, and on account of this on two occasions the child was given 5 gr. of chloral hydrate to induce sleep. In both these experiments a very low basal metabolism was found. Professor Pembrey suggested that this depression was probably due to the narcotic, and reference to the literature $(7,9)$ supports this view, though Tangl and Verzár (13) did not find a consistently lowered metabolism during narcosis produced by either morphia, urethane, or chloretone. Neither of these experiments, therefore, can be accepted as showing the true state of the metabolism. Eventually, by doing experiments at night, periods of repose were obtained without narcotics, and it will be seen that there was a marked rise in the metabolism compared to that found before treatment commenced-about 40 per cent.

It will be observed that though these children's ages were 2 and $4 \frac{1}{2}$ years respectively, J. D.'s weight was about equal to the expected weight of a child of 10 months, and A. D.'s to that of a child of $1 \frac{1}{4}$ years, but their heat output was only equal to that of children of about 6 months and 8 months respectively. So, whether the heat output be compared to that of a child of the same weight or the same age, in either ease they both showed a greatly lowered metabolism.

After $3 \frac{1}{2}$ weeks of treatment with thyroid J. D.'s metabolism had risen considerably, and was equal to that of a child of about 1 year old in spite of the fact that he had lost 0.5 kilo in weight. In A. D.'s case, after 5 weeks' treatment with thyroid, the metabolism had risen to that of a child of $1 \frac{1}{2}$ years and she had lost 2 kilos in weight, which was by then only equal to that of a child of about 10 months old.

These results can be summarized briefly as follows:

J. D., aged 1 year 11 months.

Before treatment weight equal to that of a child of $10 / 12$. Basal metabolism equal to that of a child of $6 / 12$.

After $3 \frac{1}{2}$ weeks' treatment, weight equal to that of a child of $8 / 12$. Basal metabolism equal to that of a child of 12/12.

A. D., aged 4 years 8 months.

Before treatment weight equal to that of a child of $15 / 12$. Basal metabolism equal to that of a child of $8 / 12$.

After 5 weeks' treatment weight equal to that of a child of $10 / 12$. Basal metabolism equal to that of a child of 18/12.

One of the striking features of both cases was that as soon as they were under the influence of thyroid, and had lost most of their myxoedematous tissue, they showed a metabolism which was higher than the metabolism to be expected from a normal child of the same weight (Fig. 1), indicating that all their active metabolic tissue required to make it function normally was a sufficiency of thyroid. Probably two factors at least caused the metabolism to be higher than would be expected from the weight. Though the children had lost most of their myxoedematous tissue it had not been completely replaced by fat, and consequently the active metabolic tissues were not 'diluted' to the normal 
extent with tissue metabolically inert. This naturally would produce an apparent increase in metabolism when compared to body-weight, just as occurs in all conditions of under-nutrition in infants $(4,12)$. Secondly, these children were developing abnormally quickly, and an abnormally large amount of energy was being expended in the manufacture of new tissue. In other words, anabolism was going on at an increased rate.

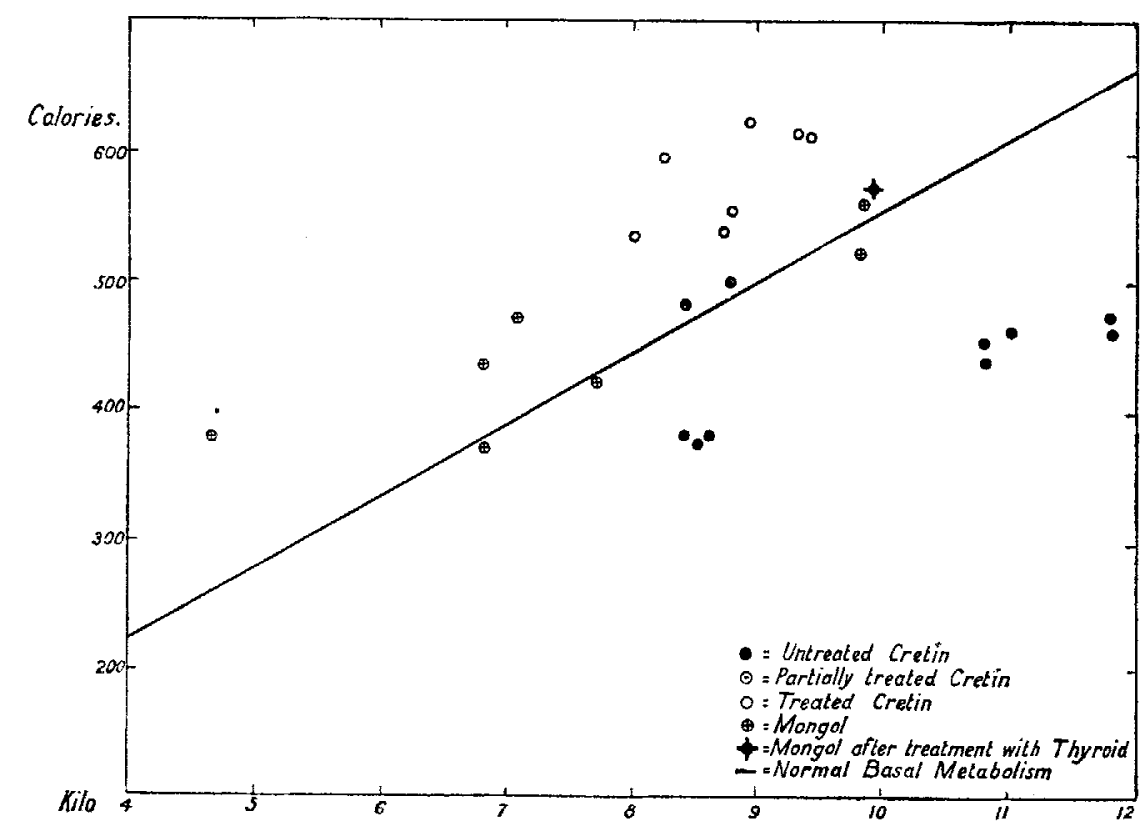

Fig. 1. The total basal metabolism per 24 hrs. referred to weight of cretins and Mongols. The continuous line represents the normal basal metabolism. (Talbot's cretin is included in this figure.)

\section{The Basal Metabolism of Mongols.}

T. S., male. A typical Mongol.

First respiratory exchange examination made when he was 10 months old; weight, 7.08 kilos; length, $65 \mathrm{~cm}$. The next at the age of 14 months, and the subsequent ones between the ages of 2 years and 2 years 5 montbs.

The child was a patient in the Royal Hospital for Sick Children from March 21 till May 4, 1922. During this time the five last respiratory exchange examinations were made. The two first examinations were made when the child was attending the out-patient department.

Except for the mental deficiency, the typical facies, the protruding tongue, and the flaccid limbs, and the great under-development no abnormality was found. 24.3.22. Weight, 9.85 kilos; length, 78.5 cm.; sitting height, 48.5.

Sugar tolerance test. $46 \mathrm{grm}$. glucose given fasting-no glycosuria ; three days later, $70 \mathrm{grm}$. glucose given fasting-gly cosuria resulted.

Thyroid gr. $\mathrm{j}$ thrice daily was given from March 24 till May 4. There was no change in the mental or physical conditions of the child during this period.

J. M.C., male, aged 12 months.

Admitted to the Royal Hospital for Sick Children on 13.12.21, suffering from broncho-pneumonia. 
On admission he was seen to be a typical Mongol, with slanting eyes, marked epicanthic folds, stiort bent little fingers, pointed protruding tongue, and great flaccidity of muscles. The heart seemed normal. There was a harsh respiratory murmur and râle at the bases of both lungs. Ears appeared normal. There was conjunctivitis and a considerable degree of nasal obstruction. Urine normal, von Pirquet reaction negative. He was poorly nourished; weight, 4.70 kilos; length, $64 \mathrm{~cm}$.; sitting height, $42.5 \mathrm{~cm}$.

The attack of pneumonia was mild, and the child made a good recovery. On Jan. 13 temperature (rectal) rose to $101^{\circ}$, and on Jan. 15 a typical measles rash developed. The child was sent to a fever hospital. The respiratory exchange experiments were done when the child was convalescent from pneumonia.

M. S., female, aged 1 year and 2 months.

Admitted to Royal Hospital for Sick Children 1.5.22. A typical Mongol. A very small well-nourished child, skin clear. Slight bronchitis. Heart appeared normal. No teeth, abdomen normal. Slight conjunctivitis and blepharitis. Much nasal obstruction. Throat red. Weight, $7 \cdot 0$ kilos ; length, $68 \mathrm{~cm}$.; sitting height, $45 \mathrm{~cm}$.

J. M`D., female, aged 2 years 2 months.

Out-patient. A typical Mongol. Weight, 7.2 kilos; length, $74.5 \mathrm{~cm}$. A fairly well-nourished child. Physical examination revealed no abnormality.

E. M'N., female, aged 20 weeks.

Out-patient. A typical Mongol. Weight, 4.0 kilos; length, ?. A wellnourished child. Physical examination negative.

E. R., female, aged 9 months.

Out-patient. A typical Mongol. Weight, 3.71 kilos; length, $55 \mathrm{~cm}$. Fairly well nourished but very small. No abnormality found on physical examination.

Table II gives the results of the respiratory exchange experiments in these six Mongols.

In J. M'C. three observations were obtained, but in only one of them was the condition such that an estimate of the basal metabolism could be made, for in the second experiment the child was very restless, and in the third, though sufficiently quiet, he had a temperature of $101^{\circ}$ and developed a measles rash the next day. Examinations of T. S. were made from the age of $10 / 12$ to $27 / 12$, and as a rule satisfactory conditions of repose were obtained. This child is of special interest as most of the observations were made when the age and weight were almost the same as those of the cretin J. D. Four examinations of M. S. were made, and in two of them satisfactory conditions were obtained. In the other three cases, in each of whom only a single observation was made, there was too great muscular activity to gauge the basal metabolism.

All these children show a metabolism which is lower than would be expected for children of the same age, but a metabolism approximately equal to or above that which would be expected for normal children of the same weight (Fig. 1). The height of their metabolism depended on the degree of development. Thus J. M'D., aged 2 years, whose weight was equal to that of a child of about $6 / 12$, had the metabolism that one would expect from a 
normal child of that weight, taking into consideration the fact that there was some activity during the experiment.

The very poorly-nourished subject (J. M'C.) had a heat output per kilo which was higher than normal, and this is in accord with what is found in all under-nourished children $(4,12)$. On the other hand, T. S. and M. S., who were well nourished, each had a basal heat output per kilo of body-weight which was almost normal (Fig. 1).

The examinations of $J . \mathrm{M}^{\circ} \mathrm{C}$. are of interest, for on the last examination he had a temperature of $101^{\circ}$, the commencement of an attack of measles. On this day the metabolism was unduly high, showing that in Mongols fever causes a rise in the metabolism similar to that found in children of normal development (5).

\section{The Effect of Thyroid Treatment on Mongolism.}

Although no glandular extracts seem to affect Mongolism to any great extent Thursfield (14) is of opinion that thyroid does good in some cases. In view of this $T$. S. was given thyroid for five weeks and his basal metabolism determined at the end of this course of treatment. It will be seen from Table II that there is practically no rise in the metabolism, his total metabolism before treatment averaging 540 calories, and after treatment 565 calories per day. During treatment it was 603 calories per day, but on this occasion there was an activity of III which would be quite sufficient to account for the increased output on that day.

\section{The Basal Metabolism of Cretins and Mongols Compared.}

1. Both Mongols and cretins have a basal metabolism lower than that of normal children of the same age. This is largely due to the fact that in both cases there is retarded development.

2. Mongols have a basal metabolism as high as, or bigher than, that of children of the same weight (Fig. 1). The under-nourished Mongol has a metabolism similar to that of any under-nourished child. On the other hand, the untreated cretin's metabolism is lower than that of a normal child of the same weight (Fig. 1). This is partly due to the fact that the cretin's body is to an abnormally great extent composed of tissue which is metabolically inert, but also it is probable that what active metabolic tissue there is works on a lower plane of activity than normal. The fact that after three weeks' treatment with thyroid J. D.'s metabolism rose 42 per cent., and after five weeks' treatment A. D.'s rose 38 per cent., is in favour of this hypothesis. The raised metabolism was prohably in part due to the fact that growth was proceeding abnormally rapidly, but this heightened metabolism, when compared to body-weight, is a feature of all conditions where there is malnutrition, for in such cases there is a lessened amount of inactive metabolic tissue to 'dilute' the active tissue and consequently the body-weight: basal metabolism ratio appears high.

[Q. J. M., Oct., 1922.] 
3. Whilst treatment with thyroid raised the metabolism in cretins it had no effect in a Mongol.

\section{The Basal Metabolism as an Index of Nutrition.}

The consideration of these experiments raised the question whether the rate of basal metabolism when compared to body-weight gives us an index of nutrition. There is no doubt that the weight to height ratio as a standard of nutrition gives no idea of relative proportions of metabolically active to metabolically inactive tissue, and in ideal states of nutrition there should be a definite relationship between these. The only method which can give us this information is the basal metabolism body-weight ratio. In ordinary cases of malnutrition in infants, growth in stature is not affected to nearly so great an extent as growth in weight, but in both cretinism and Mongolism there is always defective growth in stature, while the weight may be equal to the expected weight for the height. In short, they are always small, but they may or may not be undernourished.

Children suffering from these diseases, therefore, seem to afford us an opportunity of testing whether the basal metabolism gives us an index of nutrition. In cretins, however, a complication arises, for they are known to have an abnormally low basal metabolism due to lack of thyroid; but if this deficiency can be made good and their metabolism restored to the normal level, then they should fall into line with infants with a normal metabolism, and the height of the metabolism referred to weight should give us an index of their nutrition.

Benedict and Talbot (2) have demonstrated that up to about 12 kilos bodyweight the basal metabolism of normally developed children is remarkably constant, about 55 calories per kilo per day. It has also been shown that children in varying degrees of emaciation have a heat output per kilo which increases with the degree of emaciation $(4,12)$. Both cretins and Mongols are undersized for their age and their weight to age ratio is no indication of the state of nutrition;" but, if the weight-sitting height ratio (Pelidisi) according to von Pirquet's (8) formula ${ }^{1}$ be determined, a better idea of the state of nutrition is obtained. Before treatment with thyroid A. D.'s Pelidisi was 98 and her heat output 41 calories per kilo for twenty-four hours; but at that time, owing to lack of thyroid, her metabolism was being carried on at an abnormally low rate. After five weeks' thyroid treatment her Pelidisi was 89, indicating a certain degree of malnutrition, whilst her metabolism was 70 calories per kilo per day. Before treatment J. D.'s Pelidisi was 98 and his heat output 44 calories per kilo per day. After four weeks' treatment with thyroid his Pelidisi had fallen to

1 This formula is: Pelidisi $=\frac{\sqrt[s]{10} g}{S i}$, where $g=$ weight in grm. and $s i=$ sitting height. 100 represents a condition of normal nutrition. The lower the figure the greater the malnutrition. 
92 and his heat output per kilo per day had risen to 67 calories. At first, in neither of these two cases did the ratio of heat output to body-weight give a true indication of the state of nutrition, because they were both suffering from a disturbance of metabolism due to lack of thyroid ; later, however, when they had been treated with thyroid, the heat output per kilo of body-weight was about what would be expected from equally under-nourished children who had no disturbance of metabolism.

If in Mongolism there is no disturbance of metabolism, then, in spite of the fact that they are invariably undersized, we would expect to find that their basal metabolism follows the normal curve. That is to say, if they are undernourished, they should have a heat output above that of a normal child of the same weight, and the same as that of any equally under-nourished child of the same weight, while if adequately nourished their heat output should be the same as that of a normal well-nourished child of the same weight. J. S. was well nourished, he had a Pelidisi of 96 , and his heat output per kilo per day was almost exactly what would be expected of a normal child of that weight. On the other hand, J. M`C.'s Pelidisi was low (86), and his heat output was above normal for a normal child of the same weight but about what would be expected of any equally under-nourished child.

We thus see that the small Mongol with a normal Pelidisi had a normal metabolism, while the small cretin, which before treatment also had a normal Pelidisi, had a very low metabolism owing to the lack of thyroid, but after treatment, when its Pelidisi was low, the metabolism was above normal. From these considerations it is possible that in the absence of disease such as hypothyroidism or lever the basal metabolism rate gives an accurate method of gauging the state of nutrition; though until more rapid and easy methods are devised the basal metabolism rate cannot be of practical value for this purpose.

\section{Summary.}

1. The basal metabolism was found to be unduly low in the untreated cretin. Thyroid treatment raised the metabolism to about the normal level.

2. The basal metabolism was normal in six Mongols. Thyroid treatment had no effect on the basal metabolism of a Mongol.

3. Fever caused a rise in the metabolism of a Mongol.

4. The results of these respiratory exchange experiments in cretins and Mongols are used to test the suggestion that the basal metabolism rate referred to body-weight gives a reliable index of nutrition.

I have much pleasure in recording my thanks to Dr. Leonard Findlay and Professors Noel Paton and Catheart for much valuable assistance and advice, and to the Medical Research Council, who defrayed the expenses of this investigation. 


\section{TABLE I.}

\section{Cretins.}

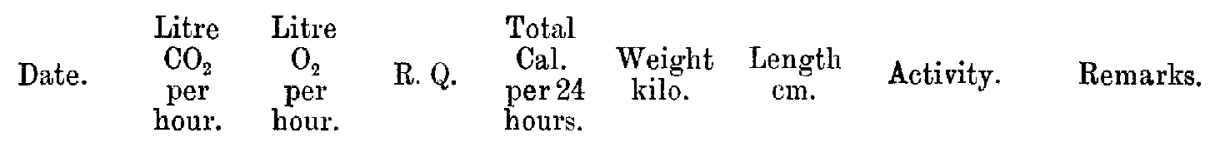

J. D.

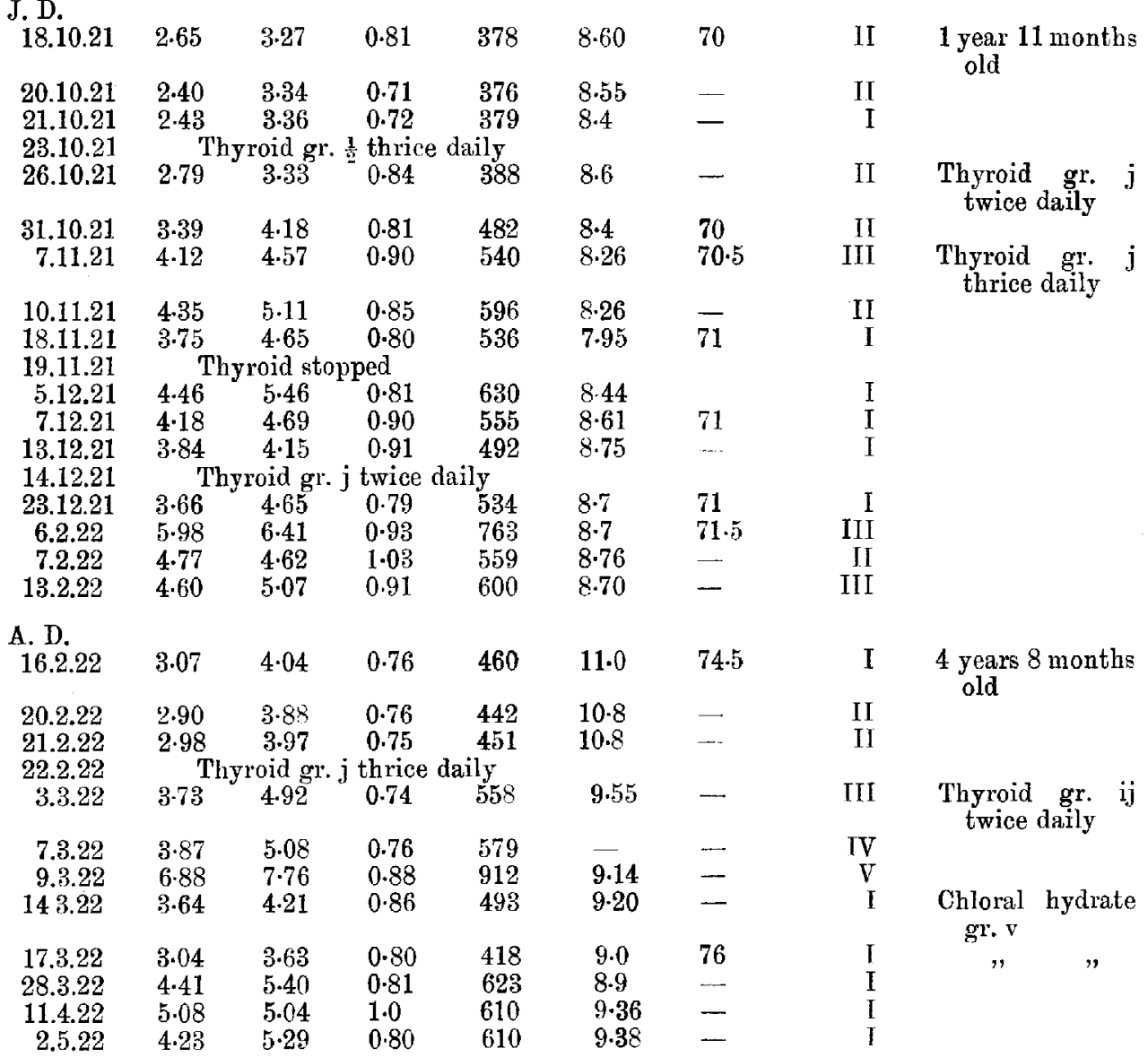




\section{Table II.}

\section{Mongols.}

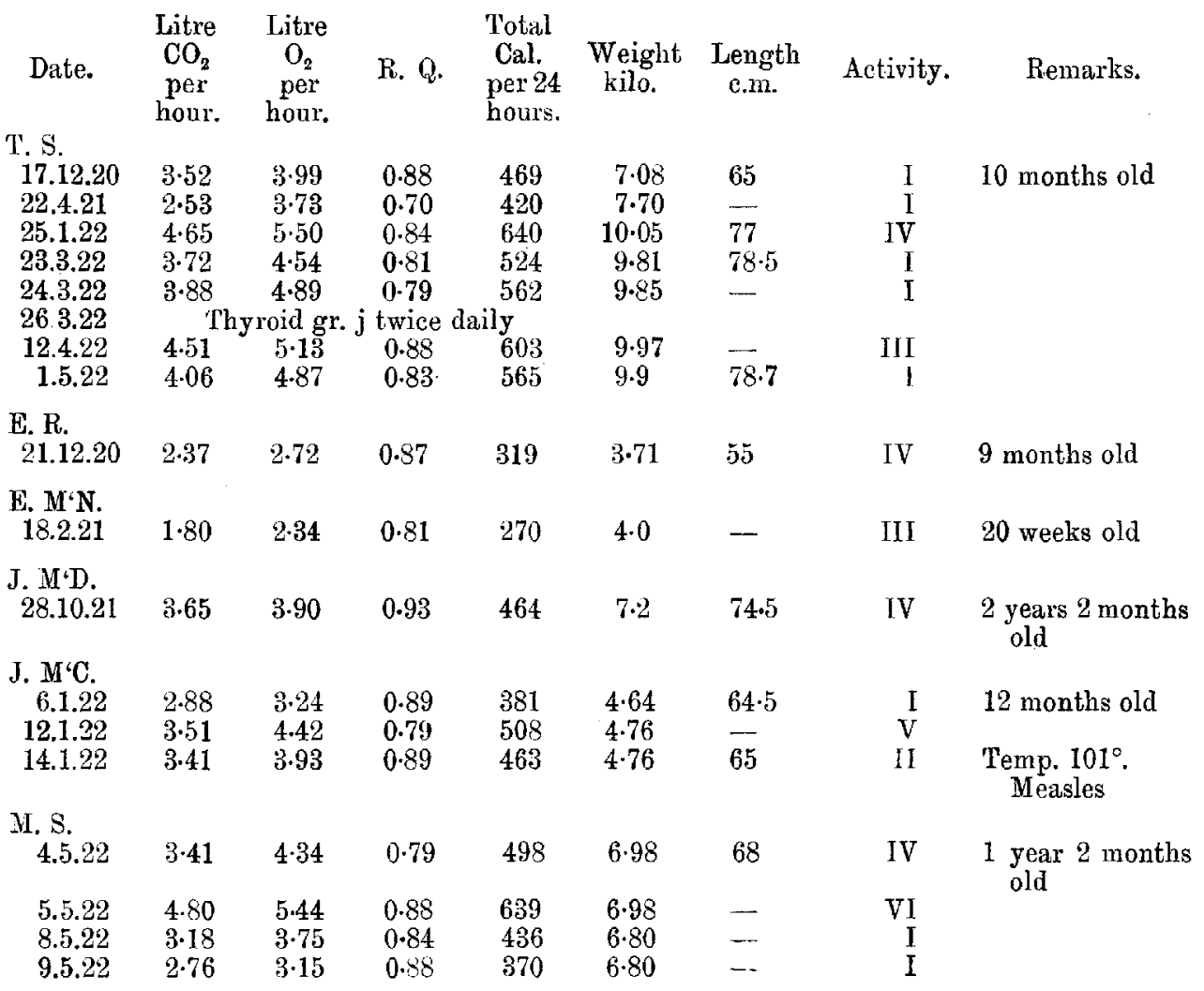

REFERENCES.

1. Albutt, and Rolleston, System of Med., 2nd edit., Lond., 1910, viii. 377.

2. Benedict and Talbot, Carnegie Institute of Washington Publications, 1921.

3. Boothby, Journ. Amer. Med. Ass., 1921, lxxvi. 84.

4. Fleming, Quart. Journ. Med., Oxford, 1920-21, xix. 171.

5. Fleming, Glasgow Med. Journ., 1921.

6. Lusk, Science of Nutrition, 3rd edit., Philad. and Lond,, 1919.

7. Von Noorden, Metab. \& Pract. Med., Lond., 1907, iii. 984.

8. Von Pirquet, System der Ernährung, Berlin, 1919, ii. 288.

9. Schäfer, Text-Book of Physiology, Edinb., 1898, i.

10. Seigert, Ergeb. der Inn. Med. und Kinderheilkunde, Berlin, 1910, vi. 596.

11. Talbot, Amer. Joum. of Dis. of Child., Chicago, 1916, xii. 145.

12. Talbot, ibid., Chicago, 1921, xxii.

13. Tangl und Verzár, Biochem. Zeitschr., Berlin, 1918, xcii. 318.

14. Thursfield, Brit. Joum of Child. Dis., Lond., 1921, xviii. 18-21. 